


\title{
Internationalizing the Higher Educa- tion Curriculum: An Emerging Model for Transforming Faculty Perspectives
}

\author{
Sabine Schuerholz-Lehr \\ Catherine Caws \\ Geraldine Van Gyn \\ Alison Preece \\ University of Victoria
}

\begin{abstract}
This article reports the findings of a university's pilot project documenting the impact of an intervention entitled Course (Re)design for Internationalization Workshop (CRIW) on faculty perspectives and their subsequent willingness to engage in internationalization of the curriculum. Two main theories, transformative learning (Mezirow, 1991) and faculty development (Ramsden, 2003) in the approach adopted for the CRIW (Saroyan \& Amundsen, 2004) informed this study and its procedures. This theoretical framework is congruent with Bennett's (1993) developmental model of intercultural sensitivity. Data collection for this study consisted of pre- and post-CRIW questionnaires, interviews, and workshop artifacts. Interpretative qualitative analysis of the data showed that faculty engaged in the process at a very deep level and reported intellectual changes in their perspectives. Also, they demonstrated a willingness to change their conceptual and practical understandings of the process of internationalization of the curriculum. In conclusion, we found that the participants' transformation and perspectives were in line with the theoretical bases of the original intervention designed by Saroyan, Amundsen, McAlpine, Weston, Winer, and Gandell (2004). Also, this pilot project reiterates the need for curricular reform, faculty development, and institutional structures to support internationalization of the curriculum on a larger scale.
\end{abstract}




\section{RÉSUMÉ}

Cet article présente les résultats d'une étude pilote visant à mesurer l'impact d'un " atelier pédagogique pour l'internationalisation des cours " sur les perspectives des enseignantes et enseignants ainsi que sur leur volonté d'accroître la dimension internationale de leurs cours à l'université. La méthodologie adoptée pour organiser l'atelier s'inspire du travail de Saroyan \& Amundsen (2004) et repose principalement sur deux théories : l'apprentissage transformateur (Mezirow, 1991) et le développement du corps professoral (Ramsden, 2003). Notre cadre théorique s'inscrit également dans la continuité des travaux de Bennett (1993) sur les modèles de croissance de la sensibilité interculturelle. Les données ont été recueillies par questionnaire (avant et après l'atelier) et entrevue, et les documents produits lors de l'atelier ont aussi été analysés. Une analyse qualitative révèle que les enseignants participants s'engagent à fond dans le processus d'adaptation de leurs cours et que leurs perspectives sur le concept d'internationalisation se transforment au niveau cognitif. Nos participants ont par ailleurs fait preuve d'une volonté évidente d'altérer leur compréhension pratique et conceptuelle du processus d'internationalisation du curriculum. En conclusion, cette étude montre que la transformation vécue par les participants, tant sur le plan de leurs perspectives que de leur compréhension du processus, correspond avec les bases théoriques sur lesquelles repose le travail original de Saroyan, Amundsen, McAlpine, Weston, Winer, and Gandell (2004). En outre, notre étude pilote démontre le besoin de renouveler nos programmes, d'encourager le développement professionnel des professeures et professeurs d'université et d'instituer des structures permettant le soutien de l'internationalisation du curriculum à plus grande échelle.

\section{INTRODUCTION}

A crucial element of internationalization is the international dimension of the curriculum and teaching/learning process. In many ways, it is the most challenging aspect to implement in Canadian institutions and it is certainly the most difficult to monitor and measure. (Knight, 2000, p. 45)

Internationalization is "a process that prepares the community for successful participation in an increasingly interdependent world" (Francis, 1993, p. 5), a world in which there has been rapid development of a global political economy, significant adjustments in international relations, and a notable shift in the demographic profile of most nations (Huang, 2003; Maidstone, 1995). The opportunities and challenges afforded by the cultural and linguistic diversity of contemporary life now mean that an internationalized education for post- 
secondary graduates is an educational imperative for success (Bond \& Thayer Scott, 1999; Jones \& Sobiecki, 2002). Strategic documents of many Canadian universities give prominence to the goal of preparing internationally and interculturally literate graduates. Changing demographics of the Canadian population, an increase in access to higher education by domestic and international students, as well as active recruitment of international students into Canadian university programs, have resulted in a substantial increase in the cultural diversity of the student body (Bartell, 2003). Hence, academic institutions are seeking ways to promote the integration of international elements into their curricula, research, and service functions.

In university programs, the curriculum is one of the key elements in preparing both domestic and international students to engage in public, community, and economic segments of a global society (Bond, Qian, \& Huang, 2003). Curriculum decisions affect both course content and instructional methodology and, therefore, influence the learning experiences of students. These experiences, in turn, shape students' ways of thinking about knowledge, how they see themselves and others in relation to knowledge construction, and their general understanding of the relationship of knowledge to social justice, equity, and inclusion (New London Group, 1996). As course curricula are generally the purview of faculty (Bond, Qian, \& Huang, 2003; Taylor, 2004), internationalized education is critically dependent upon the understanding of faculty about the scope and benefits of internationalization and their willingness and capacity for curricular change. However, a Canada-wide study of internationalization at Canadian universities (Knight, 2000) found that the majority of faculty had no process to review and assess the international and intercultural dimension of courses and programs offered at their respective institutions. We suggest that this finding reflects the limited perspective on internationalization of a significant number of faculty members. This is compounded by their insufficient pedagogical preparation to engage in substantive curriculum assessment and modification. Unless these limitations are addressed, the touted goals of curricular reform will not be realized.

In this article we report our experiences and findings from implementing a week-long faculty development institute, the Course (Re)design for Internationalization Workshop (CRIW), that was offered to enable faculty to re-conceptualize and re-craft one of their courses from an internationalized perspective.

Internationalization of the curriculum refers to a broad range of initiatives that encompasses such diverse elements and activities as the infusion of content from various cultures, curricula in foreign languages, curricula that specifically address training in cross-cultural and intercultural skills, curricula leading to joint or double degrees, and curricula aimed explicitly at international students (Bremer \& van der Wende, 1995). Despite its widespread use, the term "internationalization" continues to evoke debate and means different things to different people (Green \& Olson, 2003; Maidstone, 1995; Schoorman, 2000). This range of perspectives was reflected in the readings provided for the CRIW. In 
order to minimize confusion for the workshop participants, we presented the following working definition of "curricular internationalization" at the outset: a process by which international elements are infused into course content, international resources are used in course readings and assignments, and instructional methodologies appropriate to a culturally diverse student population are implemented. We based our approach on the assumption that a systematically internationalized curriculum would enable students to become internationally literate and interculturally sensitive citizens.

Our initial definition of internationalization proved to be problematic and was challenged by the participants throughout the course. We quickly abandoned the idea that a meaningful discussion of a course (re)design process for internationalization could take place without providing space for a dialogical process that allowed participants and facilitators to problematize the dominant terminology and to create meaning around the concepts embedded in and related to internationalization. In particular, participants struggled with the relationship between international or internationalized curricula, on the one hand, and intercultural or multicultural education, on the other.

There is a considerable body of literature on the meaning of internationalization, dimensions and requirements for internationalization in higher education, and descriptions of good practice. Several studies document the uncertainty about, or disinterest of, faculty in internationalizing courses and teaching practices (Bond \& Thayer Scott, 1999; de Wit, 1999). However, a systematic study of faculty as agents of curricular change for internationalization is clearly a neglected area of research (Curro \& McTaggart, 2003; Eisenchlas \& Trevaskes, 2003). Also, there has been little study of specific educational strategies to support faculty in curricular change for internationalization. This is not particularly surprising as the corpus of research on faculty roles in teaching-related activities in higher education is, in itself, somewhat limited in comparison to that on teaching in K-12 settings. As a consequence, there appear to be insufficient theory, theory-guided methodologies, or both, and practices to fully understand the perspectives of faculty in the process of internationalization and their capacity for change. Therefore, many intervention initiatives, although well intentioned, are rather piecemeal and have not yet resulted in the needed changes.

Notable in the literature on teaching in higher education is the work of Saroyan and Amundsen $(2001 ; 2004)$, and McAlpine and colleagues (e.g., McAlpine \& Harris, 2002; McAlpine \& Winer, 2002). The general focus of their research is on understanding the process of teaching development among university faculty members and the impact of various factors and educational interventions on the capability of faculty to design and implement curricular change. Their findings have culminated in an innovative educational intervention, which they refer to as the Course Design Workshop (CDW). This intervention is informed by two theoretical frameworks (Saroyan, Amundsen, McAlpine, Weston, Winer, \& Gandell, 2004): transformative learning (Mezirow, 1991) and teacher growth, in particular the conceptualizations by Ramsden (2003). A prominent view in 
the theory of transformative learning is that changes occur in the perspective and actions of adults only when they critically reflect on their assumptions in order to ascertain the validity of those assumptions in the current context (Saroyan, et al., 2004). By creating opportunities for faculty participating in the CDW to examine their personal assumptions about teaching, learning, and the educational enterprise, the intention was to support significant change in their subsequent pedagogical actions. The CDW is grounded on the fundamental premise that transformative learning grows out of critical reflection and leads to the construction of qualitatively new perspectives and paradigms for action (Illeris, 2004). The CDW provides a context and stimulus for faculty to examine critically their assumptions about their subject matter, their teaching, and their expectations about learning and learners (Saroyan et al., 2004).

As well, the CDW design exploits the power of communities of practice (Wenger, 1998) to initiate and support critical change. The intensive nature (40 hours over a five-day period) of the CDW presumes, from the agreement of the faculty to participate, the motivation and psychological resources to adapt to the perturbations associated with the challenge to entrenched perspectives and long-held beliefs (Bennett, 1993). Research on this intervention suggests that it has significant effects on both an intellectual and practical level and that the effect increases over time (Amundsen, Saroyan, \& Frankman, 1996; McAlpine \& Harris, 2002).

\section{An Emerging Model for Internationalizing the Curriculum in Higher Education}

In exploring potential educational interventions for facilitating change in faculty perspectives on internationalization in curricular practice, we regard the CDW as the most robust and theoretically informed vehicle to address our concerns. However, the concepts embedded in the CDW are mainly concerned with methodological processes and do not critically scrutinize the political, ethical, and cultural frameworks upon which a curriculum is based. For the purpose of heightening awareness of and challenging those underlying frameworks, we conceptually expanded the CDW to incorporate a global dimension into the teaching and learning process. In doing so, we retained key theoretical and structural features of the CDW and introduced additional elements that focused on the internationalization of current course curricula. The features retained were as follows:

- preparatory current readings on student-centred curriculum design;

- $\quad$ strategically interwoven, task-specific, collegial interaction;

- a focus on four fundamental aspects of curriculum design (content, learning outcomes, instructional strategies, and assessment) and the need to align these elements;

- sufficient time and structure for critical reflection and planning for revision of current practice;

- documentation of participants' contributions to support participant reflection (i.e., video taping and production of artefacts); 
- reciprocal response, analysis and critique by participants from different disciplines;

- in-depth interaction with multiple facilitators.

In the conceptually expanded CDW, which we labelled the Course (Re)design for Internationalization Workshop (CRIW), we built in opportunities for participants to become aware of disciplinary biases, the dominance of Eurocentric perspectives, and the need for culturally sensitive pedagogical practices. The new elements incorporated into the CRIW were

- current readings from the literature on internationalization to provide a frame of reference and common ground for discussion;

- interactive exploration of the varied and contested meanings of internationalization;

- discussion of pedagogical principles that support an orientation to world-mindedness;

- re-envisioning the four fundamental features of curriculum design through an "internationalization lens";

- strong encouragement of all faculty and other instructional staff engaged with a particular course to participate as a team.

The design of the sessions and the conceptual framework used to interpret the data were informed by the principles of transformative learning (Mezirow, 1991) and are congruent with Bennett's (1993) Developmental Model of Intercultural Sensitivity. Both theorists conceptualize such learning as dynamic, disorienting, personally meaningful, critically reflective, iterative and integrative. Bennett's model outlines a general, although not linear, progression of increasing awareness and expanded understanding that moves through initial stages of denial, defensiveness, and minimization to acceptance, adaptation, and integration. As our goal was to stimulate genuinely transformative learning, the sessions were carefully designed to provoke and support collegial reflective analysis, and to invite the continuous re-evaluation and reworking of concepts and their practical applications. According to Mezirow (1991), reflecting on generally accepted assumptions leads to the assessment and reassessment of our beliefs and thus creates an ideal learning environment for progressive learning. In attempting to determine the impact of the CRIW, we also sought evidence of the cognitive, affective, and behavioural indicators suggested by Bennett's model. These include evidence of cognitive dissonance, dissatisfaction with previous conceptions and practices, challenges and resistance, intense interactions, emotional and intellectual engagement, increasing appreciation of the complexity of the undertaking, and deepening recognition of a capacity to take action to integrate the new insights. 


\section{RESEARCH DESIGN}

\section{Field-testing of the Internationalized Model}

Although there is significant empirical support for the educational efficacy of the original CDW, the CRIW was sufficiently different to warrant a multi-dimensional qualitative assessment of its effectiveness and potential for generating pedagogical changes with respect to internationalization. Therefore, we planned a prototypical CRIW, which we infused with extensive and varied data gathering opportunities. Congruent with Ramsden's (2003) principle that in order to improve teaching we must reflect on how "we think about teaching and experience teaching" (p. 7), our purpose was to qualitatively document the impact of this particular CRIW as a vehicle for internationalizing curricula and to assess changes in faculty participants' perspectives on internationalization and their willingness to engage in internationalization of their courses. A secondary purpose was to evaluate the viability of the conceptually expanded workshop model in this context.

Co-facilitated by representatives from the University of Victoria's Learning and Teaching Centre and the Office of International Affairs, the prototypical CRIW was offered in the spring of 2004. An external international education specialist was involved in the collaborative planning for the CRIW and participated in the workshop. Her role was to provide a theoretical framework for the concept of internationalization which was subsequently connected to the various aspects of course (re)design.

\section{Participants}

Five regular faculty members representing five courses participated in the CRIW. These courses were

1. Global Software Development (graduate course, Department of Computer Science)

2. Contemporary Literacies and Creative Expression: Theoretical Underpinnings (undergraduate course, Department of Curriculum and Instruction)

3. Integrated Language Strategies (undergraduate course, Department of Curriculum and Instruction)

4. European Integration: Socio-Economic and Political Developments (undergraduate course, Department of Political Science)

5. Social Psychology (undergraduate course, Department of Psychology)

In total, there were 10 participants in the workshop as two faculty members included three teaching assistants involved in their respective courses, one sessional instructor participated as part of a team, and one faculty member included a staff person (program co-ordinator). All participants were female. 


\section{Procedures for Data Gathering and Qualitative Analysis}

The procedures involved multiple sources and data collection points before, during, and after the workshop. To ensure the internal validity and coherence of the study findings, we triangulated the various data sources to identify and confirm converging themes and recurring patterns. Throughout the workshop sessions and during a post-workshop focus group, we systematically checked our interpretations for accuracy with the original workshop participants (Miles \& Huberman, 1994). The themes that emerged were compared with the previously noted conceptualizations of transformative learning (Mezirow, 1991), teacher growth (Ramsden, 2003), and intercultural sensitivity (Bennett, 1993).

Prior to the CRIW, all participants completed a pre-workshop questionnaire that probed for their understanding of internationalization and requested they identify the instructional methods and learning outcomes for the courses to be redesigned. This questionnaire was returned along with current course outlines and descriptions of assignments. Each of these sources was used to gain an understanding of the perspectives of the faculty members on internationalization in general and on internationalization of the curriculum in particular. Prior to the workshop and to inform the design of the sessions, the facilitators collaboratively analyzed the responses for recurrent themes and omissions. The course materials were reviewed both for evidence of internationalized elements and for the instructional approaches adopted by the participants. These initial interpretations were presented to the participants in the first workshop session for confirmation of accuracy. In addition, all pre-workshop data were retained for comparison to data gathered during the workshop, and during a post-workshop focus group.

During the CRIW, participants gave written feedback to the facilitators at the end of each of the first four days of the workshop, guided by the following four questions:

- What's new?

- What has changed?

- What do you need?

- What are your thoughts or reflections on internationalization?

Responses to these informal questions were reviewed by the facilitators and themes were identified. Summaries of the feedback received from the previous day were presented in the morning of each following day in order to allow for modifications to the activities where possible and to enable facilitators to address areas of concern or uncertainty. This process was useful in determining the effectiveness of the CRIW in attaining the goals of the intervention and identifying where adjustments needed to be made. In addition, it provided room for a dialectical interpretation of the thinking processes of participants (Mezirow, 1991).

Each day, participants worked on particular curricular topics (content development, learning outcomes, instructional strategies, formative and summative assessment methods) and at the end of the day presented their progress to 
their peers. Each of these presentations was video-taped and presenters received feedback on the clarity of their work and the degree to which the work reflected progress towards inclusion of international components and perspectives. Participants were given the videotape to review before the next day of the workshop. The videotapes then became part of the data collected for the purpose of identifying changes in perspectives on internationalization and on teaching and learning.

During the daily process of engaging with curricular decisions, the participants produced lists, maps, diagrams, and other forms of documentation on flip chart paper that were either physically retained by the facilitators or digitally photographed. Of particular value, both to the facilitators and participants were the concept maps of course content that participants developed and presented to their peers. These maps became a "touchstone" for participants who returned to them repeatedly, often struggled to articulate the concepts embedded in them, and in some instances modified them throughout the course. This reiteration provided grounding for collegial assessment and reassessment and opportunities to diagnose misunderstanding or to identify changes in understanding of concepts or selves (Ramsden, 2003). The maps also usefully informed our analysis: those maps produced in the first workshop session were checked against the themes that had emerged from the pre-workshop data gathering. Subsequent versions of the concept maps were checked against previous versions and thus provided a visual representation of the participants' evolving perspectives on curriculum internationalization.

Facilitators took part in daily debriefing sessions to identify and track any changes in engagement by participants, as well as to record any emerging areas of uncertainty. The debriefing sessions also provided an opportunity for facilitators to cross-check their ongoing analysis and to ensure internal coherence of the findings. On the final day of the workshop, participants presented a comprehensive overview of their progress on their (re)designed course together with a proposed course outline, which became a significant part of the data set.

Two weeks after the CRIW, summative feedback was collected from seven of the $10^{1}$ participants through a 13-item questionnaire. Eleven questions invited open responses, and the remaining two questions asked the participants to evaluate their knowledge about teaching and learning for global literacy before and after the workshop using a 10-point Likert scale. Information gained from these questionnaires was cross-checked with the daily formative feedback and the concept maps. Considering the exploratory nature of our study and the small sample size, our analysis did not warrant data reduction through tallying and categorizing.

Fourteen weeks post CRIW, facilitators met with nine of the 10 CRIW participants in a focus group to discuss the latter's progress towards implementing the proposed changes, the challenges encountered, and resources needed to continue. Several CRIW table facilitators also participated in the session. This meeting was recorded and all discussion was transcribed. 


\section{FINDINGS}

\section{Pre-Workshop Questionnaire}

The reported teaching formats of the courses involved in the CRIW were quite varied and included lecture and discussion, team-taught, lab-based, and geographically distributed classes using Internet and video conferencing technology. Only two of the courses contained any learning goals that made reference to international elements.

Asked about perceived obstacles to good teaching, some participants identified, among others, the diversity in background of the students, their own lack of awareness of the students' perspectives and social worlds, and the continual challenge of creating a learning environment in which students found the material interesting, relevant, and accessible.

In response to the question about their concerns regarding teaching, the major issue for participants appeared to be designing appropriate exams and assignments that tested for critical thinking and enabled the students to apply the concepts that they had learned while remaining manageable in terms of the marking demands placed on the teacher. Participants were probed for their current perspectives on internationalization and their understanding of the implications of this concept for curricular design. Answers were categorized around the following topics regarding internationalization and curricular design:

- inclusion of cultural differences in the discipline;

- inclusion of examples from a range of geographical regions;

- making the material accessible and relevant to all students;

- helping Canadian students appreciate different points of view;

- inclusion of international students' perspectives and of international professors/speakers;

- raising Canadian students' awareness of how their learning has become more "internationalized."

Participants were asked to identify teaching strategies they had used in the past or were planning to use that might be consistent with an international perspective. Only three participants answered this question. One reported that she used class discussion about the influence of culture and encouraged students throughout the course to think about how different concepts in that discipline might be affected by culture. Another participant cited in-class demonstrations that would help students see an issue from a different cultural vantage point. A third respondent referred to strategies such as including international students and international speakers, being explicit about international learning outcomes, and putting the content into perspective with respect to geographical and cultural differences. Although participants saw the need to use teaching strategies that included an international perspective, most participants were quite uncertain about how to do this. For those who gave examples, it appeared that they relied on students to raise and explore the implications of cultural issues. The limited response to this question indicated a need to support the 
capacity of faculty members to design and incorporate effective strategies to make cultural concepts tangible and relevant for students.

The final question in the preparatory assessment was directed at participants' expectations regarding the CRIW. In their responses, participants wrote of their need to better understand the concept of internationalization and what it meant for their particular courses, to clarify how students might benefit from this, to be more aware of the instructional choices for delivering a course with a strong international dimension, and to learn ways to be more effective in ensuring that students achieve the desired learning outcomes. These questions were designed to help participants clarify for themselves the current state and adequacy of their understanding of internationalization and to prompt them to reflect on their current positions. In Bennett's (1993) framework, making this knowledge explicit is a necessary first step towards developing enhanced awareness and sensitivity. As well, the theoretical basis of the generic CDW includes reflective practice as a critical element in pedagogical transformation and meaning making (Mezirow, 1991) and is comparable with Bennett's assertion that those seeking increased cultural sensitivity must be willing to attribute "meaning back on to the meaning maker - a self reflectivity that is the essence of consciousness" (p. 26). The next section will describe and interpret the participants' responses to the main activities and outcomes over the course of the five-day workshop.

\section{Formative Assessment of the CRIW: Facilitator Observation and Participant Feedback}

\section{Day 1 - Mapping the Main Course Concepts}

Most of the Day 1 reflections focused on the concept of internationalization itself. Participants attempted to derive their own definitions after facilitators offered theirs. It was generally acknowledged that internationalization of the curriculum was a long-term change process with multiple dimensions that needed to be approached in a variety of ways. Participants identified a potential area of conflict with respect to the reality of differences, on the one hand, and the espoused rhetoric of community, commonalities, and inclusion, on the other.

Participants reported a clear and deeper understanding of their own course concepts and their relationships through the development of a concept map and through the process of presenting and explaining their course maps to the other participants and facilitators. This need to make one's understanding explicit is described by Mezirow (1991) as being "the central dynamic in intentional learning” (p. 99). The need to be explicit about course goals, key concepts, and content was recognized as particularly beneficial, but surprisingly difficult. Several participants raised the issue of a lack of use or availability of research material from non-Western cultures. They also raised the question of whether there should be a dividing line between traditional and internationalized content, or whether these should be integrated concepts. As participants started to explore new dimensions related to internationalization, some expressed fear about los- 
ing control as they contemplated letting go of approved or known structures in their curriculum. This type of conflict over meaning is necessary if education is to be intellectually challenging, and knowledge will emerge from engaging with contradictions and conflict. Bennett (1993) marks "a feeling of threat to the stability of one's worldview" (p. 26) as a key indicator of developmental learning. In contrast, some participants expressed excitement with respect to this new way of thinking about their courses and the potential in the diversity of instructional approaches, in particular those that focused on student-centred learning. In addition, participants stated a need to be challenged to step outside of their comfort zone and look critically at their core course concepts:

I want to be challenged to let go of the securities that I have in the course so as to do different things.

New strategies must accompany the profoundly shifting thinking about what I would like students to learn: need for more in-class activities designed to allow experiential learning to occur; need for more strategies that help connect book learning with our awareness and being in the world around us.

Challenge to discuss issues related to culture in an ethical way, without stereotyping and thus possibly hurting students' feelings.

This general state of uncertainty expressed as fear, excitement, or challenge was anticipated from the work of Saroyan and Amundsen (2004). They state that "questioning one's practice is difficult. It may involve an adjustment of one's self image, a questioning of deeply held values, and a readiness to take some risks" (p. 76).

Participants appeared to struggle with identifying ways of acknowledging international students and their prior experiences, as well as the question of how to ensure equity:

Expertise of international students and faculty on campus is not sufficiently and creatively tapped.

Students need to have equal accessibility to the material whatever their cultural background.

Think long and hard about support for ESL students in the class, and whether there are structures created in the course to connect international students meaningfully with their classmates.

I don't want international students to feel that they must contribute to the class on these topics. Some international students might not want to speak about their own experiences in class".

The process of balancing the reality of differences with the need for 
equality [at least in opportunity] seems to require conflict with the need to make people all the same. These value systems should be confronted directly and clarified.

It was very instructive to hear several participants describing negative experiences resulting from previous attempts to engage international students in demonstrating how a particular concept was culturally constructed. These instructors reported that their efforts had resulted in students feeling singledout or paraded in front of the class rather than feeling included and recognized, as had been the intent. Consequently, these participants expressed feelings of defensiveness and uncertainty as to how to proceed.

Need to know more about how to put contentious and potentially divisive issues [race, discrimination, cultural value clashes] on the table in ways that make it possible for students to feel safe and willing to discuss them.

How to set things up so conflicts are managed? How to raise issues of difference and diversity not as a problem, but as rich and real, and fundamental to our world?

This experience is consistent with the findings of Samuel and Burney (2003) who described professors' well intended, if somewhat clumsy, attempts at making students feel comfortable by acknowledging their cultural backgrounds. Borisoff (1997) described this dilemma in more general terms as the hidden dimension of culture that tends to manifest itself in multicultural classroom settings in a distortion of cues and the unintended exposure of assumptions.

Day 2 - Introduction to Learning Outcomes

Feedback on Day 2 suggested that some participants recognized the danger of reinforcing stereotypes by creating a distinction between traditional and internationalized content.

International issues cannot be treated as a separate topic that would make a "guest appearance" at various points throughout the course. These issues need to be integral to the course.

Internationalization is an integral part of the course and the manner in which it is taught.

I applaud the focus of the Workshop and the effort to infuse and permeate, rather than treat internationalization as a specialty topic that could be addressed in a specialty course.

A few participants, however, still remained skeptical about the blending of traditional and internationalized content. As one participant indicated, "I hope 
that the emphasis on internationalization in the classroom does not impede the learning of basic ideas and processes that students are coming here to learn." The focus on learning outcomes was seen as helpful; however, participants were still struggling with ways to be explicit about their learning goals and were already thinking ahead to the assessment of these goals. A participant commented that "there are some learning objectives that I might not be able to adequately assess: how do I know if there has been true shift in perspective or values"? Until they were comfortable with how the concepts in the course and their interrelationships were represented, they appeared to experience difficulty with creating learning outcomes. Participants seemed better able to align their concept maps with their learning outcomes once provided with examples of internationalized learning outcomes which they could correlate with their course goals.

The focus of participants' discussions repeatedly returned to probing the meaning of internationalization and the significance of that concept in the context of course design. As they worked to clarify their understanding, new questions arose, such as "how do I meaningfully incorporate the presence of other languages in the classroom into the teaching and learning process?" "How do I interact appropriately with students for whom English is a foreign language?" "How can my students and I gain and learn from other cultures?" A lively discussion evolved around the notion of language not just in terms of foreign language acquisition and/or proficiency, but also in regard to idiomatic and colloquial expressions and innuendos that are entrenched in our daily language use, and which may be utterly disorienting for anyone unfamiliar with them. For example, one participant noted that "in an international setting, it is critical to clarify/define the terms you are using, as the common ground that we often assume, may not exist, and meaning is grounded in cultural context." From the workshop discussions, it was clear that participants experienced culturallybased problems with domestic students as well, as these students are a product of our diverse Canadian society. Whether "home-grown" or "imported" it was evident that worldviews among students differ considerably and inevitably. The issue explored was how to capitalize on this range and richness of experience and perspective rather than ignoring it or regarding it as a problem instead of a resource.

\section{Day 3 - Continuation of Learning Outcomes}

Participants acknowledged concept mapping to be an iterative process as they found themselves returning repeatedly to revise the core concepts featured on their maps. Some participants explicitly stated that they now viewed "internationalism" as an integrated concept that needed to be infused into the course design process, rather than being a separate (and often burdensome) consideration.

Participants showed increasing awareness of the importance of the language used and were careful in their use of words that had a cultural bias. There was 
a growing understanding that the backgrounds and needs of the students in a class should be as critical a consideration as content when designing learning outcomes.

Participants reported that the dynamics of the workshop group had changed, and that they were now more receptive to other perspectives on internationalization, teaching and learning, and understood their relevance and value. Saroyan and Amundsen (2004) call this the "Wednesday phenomenon," the point at which participants "make a deeper sense of the meaning of what they have learned" (p. 90). This dimension of learning is also congruent with the theory of transformative learning which assumes that by transforming our perspectives on knowledge we move towards change through the mere process of learning (Mezirow, 1991). In addition Ramsden (2003) argued that teacher growth must include an analytical process of self-evaluation.

At this point, participants lobbied the course facilitators to deviate from the set agenda of the CRIW to allow for further exploration of complex concepts such as internationalization, multi- and inter-culturalism, diversity, and the intersection or overlap among these concepts. Consistent with Curro and McTaggart (2003), these discussions revealed an understanding of the need to move from a simply technical perception of internationalization to a much deeper understanding of international education as a framework for structures of social interaction that build new forms of transcultural existence. The iterative nature of engagement by participants with the concepts, and their explicit acknowledgement of greater appreciation of the complexities inherent in the process of internationalizing the curriculum, offer evidence of genuinely transformative and developmental learning and are congruent with the theoretical perspectives of both Mezirow (1991) and Bennett (1993).

\section{Day 4 - Exploration of Instructional Strategies}

Participants reported a general feeling of satisfaction that they were able to communicate their course concepts in a more explicit and concrete fashion, and they expressed a higher level of comfort with what they had developed so far. There appeared to be a major transformation among several participants with respect to thinking about concepts that were formerly seen as "Concept $X$ versus Concept Y," and that had now become "Concept X and Concept Y." One participant described this as a shift in "default thinking." For example, the majority position had originally been that internationalizing the curriculum addressed the needs of international students alone or of those domestic students who intended to engage in study or work internationally. Clear agreement emerged in this session that an internationalized curriculum must be student-centred to better meet the needs of all students. In the daily debrief, facilitators agreed that, as the workshop progressed, there appeared be a gradual decline in polarized thinking and an emergence of integrated thinking (Bennett, 1993), as evidenced by the referenced integration of different and contradictory concepts. 
With respect to reflections on internationalization, no major new insights were reported, but lively discussions continued to take place not only as part of the formal agenda, but also during breaks and after the workshop in the afternoons. The concept was obviously stirring up a lot of interest, emotions, and questions (Bennett, 1993). This is very fittingly summarized in the following quote from a participant: "Internationalization] is still [a] 'fuzzy concept' to me, but I enjoy probing its meaning."

\section{General Observations on the Formative Assessment}

The formative assessments made during the workshop are very much reflective of some of the common struggles associated with a student-centered model of instruction, as described by Felder and Brent (1996). In particular, these authors point to the dynamics in a non-traditional class, as well as outlining faculty concerns about sacrificing time spent on "covering" the course content in return for time-consuming student learning activities. Navigation of the realization of just what change implies for practice is a necessary, if often unsettling, part of the change process (Ramsden, 2003).

The international component infused into the regular CDW obviously added a layer of complexity to the active engagement by participants with the new model. To a considerable extent, we observed cognitive dissonance (Jackson, 2003) as instructors tried to negotiate the meaning of internationalization and attempted to differentiate it from related concepts. Jackson also points to the contradiction created by the familiar concept of globalization and attempts by many universities to respond to globalization through the adoption of a multicultural university curriculum. Some participants appeared to be more open than others to the notion of considering non-Western perspectives as valid alternative points of view.

What can we gain/learn from other cultures?

Internationalization is not simply a mechanism to help accommodate or acclimatize international students - it is a process relevant to everyone's appreciation of the limited vision we have when our filters are in place and the benefits we can gain from considering other frames of reference.

According to Jackson, such a shift is necessary in order to give internationalization a new meaning and provide for a truly multicultural debate on the future of humanity. In this context, participants questioned the concept of "Western" itself, suggesting that it perpetuates a stereotypical and homogenizing image of a culture that, in reality, consists of a vast array of subcultures and includes people who may have few common points of reference. 


\section{Summative evaluation}

The summative workshop evaluation was conducted through participant feedback forms completed two weeks after the workshop. Participants were asked whether their perspective had changed in regard to student learning outcomes, learning strategies appropriate in their courses, and student assessment methods. Participants' responses demonstrated their engagement with the topic on a very deep level. Not only did international issues and intercultural awareness become more prominent features of course design, but interdisciplinary thinking also emerged from their responses. One respondent noted "[an] enhanced appreciation of the interconnectedness of my discipline with other disciplines, and the biases of my discipline. [There is a need to] help students to appreciate the boundaries of my discipline's view on various phenomena and educate them on how to study the same phenomena from different points of view." This is consistent with Ryan's (2000) perspective that alternative cultural ways of viewing a discipline can be very important in understanding the phenomena being studied.

Several participants recognized that the presentation of diverse cultural approaches cannot be treated solely as objects of study, but rather has to be approached as living, alternative ways of world-making (Haigh, 2003). This concept is illustrated by the following statement from a respondent: "[I] hope to construct a learning experience where students go beyond learning about various phenomena and learn how they might manifest differently depending on the method of inquiry or geographical or psychological place from which they emanate." Participants also commented on a greater need for diverse assessment methods in order to measure internationally relevant learning outcomes. In particular, they identified the difficulty of measuring these outcomes with the traditional tool set and the importance of formative assessment methods given that some learning will manifest itself over time and/or outside the classroom.

All respondents reported intellectual changes in their perspectives on, and understanding of, the concept of internationalization that had taken place progressively over the course of the week. Some participants deliberated on practical ways of incorporating an internationalization approach into their courses. For example, one participant remarked that "the workshop highlighted the importance of the course outline-making the process of internationalization transparent in the outline," while others engaged at a conceptual level - "I no longer immediately think of a place on the globe when I hear 'international' or 'internationalization' -I now think of a place within the mind's eye." Some participants moved from a very mechanistic understanding of internationalization to a conceptualization that placed this process more squarely within critical pedagogy: "Recognition that internationalization is not simply a mechanism to help accommodate or acclimatize international students-it is a process relevant to everyone's appreciation of the limited vision we have when our filters are in place and the benefits we can gain from considering other frames of reference." 
Many of the discussions throughout the week focused on the intersections between internationalization and concepts such as intercultural and multicultural education. James (2005) cautions against the notion that international education automatically promotes intercultural understanding, arguing that nationality cannot be equated with culture, and that an education emphasizing international similarities and differences does not always address intra-national differences based on culture. The workshop participants addressed the notion of interculturalism as being distinct from internationalism:

[The] classroom needs to become a forum for students to understand, respect and hopefully embrace various cultural perspectives (with 'culture' defined in a very broad sense.]

[We need to] encourage students to think of intercultural differences when they learn about the discipline.

[We need to] discuss intercultural issues as they pertain to Canada.

Participants identified their key learning experiences from the CRIW and described concerns related to teaching, learning, assessment and/or course design, both from a general and internationalized perspective. In keeping with Bennett's (1993) developmental model, participants approached these questions with a heightened sense of awareness regarding a more inclusive perspective that takes into consideration different cultural backgrounds and worldviews. As outlined previously, a few participants, as illustrated by the following quote, expressed insecurity with respect to discussing issues related to culture, discrimination, and inter-group tensions in an ethically and pedagogically appropriate manner: "II] need to know more about how to put contentious and potentially divisive issues ... on the table in ways that make it possible for students to feel safe and willing to discuss them."

All participants ranked, on a scale from 1 to 10 , their knowledge about teaching and learning for global literacy/citizenship both before and after participating in the CRIW. On average, the ranking went up by two to five base points. In the overall assessment, the participants expressed special appreciation for the availability of facilitators to keep the small group discussions focused as well as for the benefits of sharing their work and receiving feedback from their colleagues both from the same and from other disciplines.

The struggle with the concept of internationalizing the curriculum appeared to be the most difficult for those teaching courses in which there was no obvious link to international issues, and where there was consequently a necessity to challenge the dominant theoretical positions in the course (e.g., Social Psychology). Nonetheless, the degree of change in the various courses was similar and, in fact, those teaching courses with embedded international aspects came to realize that they needed to broaden their perspectives on internationalization to include more appropriate and varied pedagogical elements. The differences in 
the responses to the processes of the workshop between those instructors leading such courses and those working on courses that have a clear international focus call for further study.

\section{CRIW Follow-up}

Fourteen weeks after the CRIW, participants were invited to participate in a focus group to reflect upon the impact, if any, of the (re)design process and of any other issues they wished to raise with respect to the notion of internationalizing their curricula. All participants were asked to comment on the following questions:

- Are you teaching the course that you worked on during the CRIW this fall? In the spring?

- If so, have you made any specific changes to the way you have taught the course in the past?

- If yes, could you identify these changes?

- In making changes to the course following the CRIW, what challenges did you encounter?

- Did you seek any help in overcoming these difficulties? From where or from whom?

- If you have NOT made any changes following the CRIW, what do you think are the reasons for this?

- Are you still planning to make changes to your course in the near future?

- What help do you need to implement your desired changes?

- If you have never taught the course before, have you made any changes to the way you first envisaged the course following the CRIW?

- Reflecting back on the workshop almost four months later, what are some of the feelings, ideas, aha-s, frustrations, etc., that come to mind, and have these shifted from your thinking during and immediately after the CRIW?

- Do you have any suggestions regarding the CRIW experience itself?

The complete discussion was recorded, transcribed and analyzed. The focus group facilitators jointly coded the transcript and identified patterns. Three themes emerged that dominated the discussion: awareness, willingness, and contradictions.

\section{Awareness}

Participants were very pleased with their improved understanding of internationalization and expressed this with genuine pride:

I think that I would not have paid so much attention to making people aware of the cultural differences. That is a big thing I took out of the workshop. We need to get people to learn about and discuss about 
differences and make sure those things are considered. I would have missed them otherwise.

So [I] am looking at my group and the first thing I am thinking, there are two from Europe and two from China and who is on exchange and who is here for the first time at UVic and how are they coming to this classroom and what might they expect normally. That was a major change. I used to look at gender. Now I look at diversity. It is not only visual minorities, but also a sense of whether they behave culturally integrated. ... I am much more aware of what your classroom is than what I would have been.

Increased awareness also manifested itself at a deeper level with respect to challenging deeply held assumptions and behaviour patterns, as articulated by the same participant:

It is hard to become aware of what it actually means because we have been trained in the North American [context] that presentation is incredibly important and if you have a good way of presenting yourself for some reason that is more valuable then giving exactly the same content and not presenting it quite as well. So by definition you assume if it is not well presented it is not as valuable. And that works very well if you are all working with the same starting procedure. But if you don't you are going to have to do that inverse thing, you have to say, OK, what is it that is new and different from this person's perspective despite the fact that it's not presented in the way that I am used to signaling that someone actually knows their business. (Participant V)

This awareness also enabled the participants to recognize that some of the work they had done in their courses, prior to engaging in the CRIW, was consistent with the principles of internationalization:

The other thing that I realize is that last year we had a built-in internationalization component that I only now in retrospect realize. We had a student who was studying immigrant families and looking at parents' expectations of their children and comparing that with non-immigrant families and there were two students in the room, one from Hong Kong and one from Japan.

The participants identified that they were better able to anticipate and address problems or issues associated with internationalization arising in their courses. They also commented that they were better prepared to consider alternative solutions to internationalization issues than they had been before the CRIW, and they identified the conceptual tools addressed in the CRIW (concept 
map, learning outcomes, learning-centred instructional strategies and assessing for understanding) as a critical foundation for those solutions. The opportunities in the CRIW for cross-disciplinary comparison were singled out as very instructive, and participants recognized the many ways in which the issues in the various courses were convergent. They also appreciated the input from colleagues with other disciplinary perspectives as it provoked them to think about their courses and approaches to teaching in a different way. The growing understanding of the process of internationalizing the curriculum was accompanied by a growth in understanding of the limitations placed on instructors by the infrastructure, policies, and procedures of their departments and the institution in general.

\section{Willingness}

There was a lively exchange of ideas and resources as the participants demonstrated a genuine willingness to continue to make progress in the internationalization of their courses and to contribute to the inclusion of all students. However, participants realized that curricular changes are not trivial and require careful thought and progressive implementation. Comments in this regard exemplified the "argument for a reflective and inquiring approach as a necessary condition for improving teaching” (Ramsden, 2003, p. 8). Indeed they all had come to realize that there was no "quick fix" that would internationalize the curriculum but expressed patience with the process. For example, one partipant stated that "I would like to implement it, but not have it to be "this is the day where we sit and reflect on internationalization'. I would like it to be a much more integral part of the year."

A recurring theme in the discussion was the use of language and of literature. Participants questioned paradigms they had previously accepted, positions they had previously taken, and critically investigated their classroom practice:

The topic came up about writing in another language. I explained my restrictions and I explained how an instructor has to deal with language issues-if a paper is written poorly it is difficult to differentiate between your poor language knowledge and your poor writing and it would be in a sense a risk that the student would take. ... So we had this whole debate again, and I felt much more secure, because the last time, seven years ago I agreed to accept anything I could read and I didn't know what I was saying and so subsequently encountered all these problems. Now I know the problems will be there, but I feel much more secure to say let's deal with this in a more interactive fashion, show me your proposal, what are your language skills, why do you want to write in that language, and can we see if that will work out and be aware that we will have that issue to deal with and so on. 
Several participants reported attempts to modify their practice that demonstrated a deepening recognition of the participants' capacity to take action to integrate the new insights, reflecting a key stage in Bennett's model (1993).

Furthermore and congruent with Bennett's (1993) formulations, there was also evidence throughout the CRIW of increasing emotional and intellectual engagement with the concept of culture which participants perceived to be closely linked to internationalization:

Routinely, in psychology you get to the end of the year and you present what you found and you add certain caveats or limitations (the things one hedges on before saying that what has been discovered has relevance beyond my lab or out in the real world). The whole idea of culture as being important in shaping the research question, what thoughts are entertained, the methodology used, the interpretation of the data, and just to think of that as an overarching umbrella and if I can find a place to introduce this to the group and help them appreciate the learning that can come from realizing how narrowly constrained we are in some sense of what we are doing with these research projects and so to gain that perspective.

It is not only the idea of internationalization or internationalism or multiculturalism and I need to work out how these words relate to one another and which words I would prefer to use in my class, so I am still struggling with the actual labels that I want to use and then how do I enable the students to think about these concepts really deeply so that in my planning they are not just going at it superficially to get through a half hour lesson.

\section{CONTRADICTIONS}

With their growing awareness came an increase in the ability of participants to identify contradictions, with respect to internationalization, within the institution, their particular programs, and between their own practice and their current understanding of internationalization of the curriculum. Some challenges manifested themselves in the discussion of language issues:

There really is a problem to assuming that you can use another language and think it is easy to judge it as a North American instructor. It's very difficult. Part of the problem really then becomes how do you judge something that might be culturally correct in one language and might not be considered the same value if it was in English. . . . I had a couple of really good speakers... but English was probably their third language ... with a very different way of speaking, not just the accent, but the whole rhythm and intonation. ... I try to put the perspective on why the speaker is really interesting - I give background to support 
why this is a great person to have. However, if you were just a North American student never took on anything that was strange or different, in the first five minutes you might think you don't need to know this because, it's not easy to hear so I will tune out, so you have to tell them this is where you have to put in the effort, you have to disentangle what this person is saying and after you have started concentrating you will get it.

Participants reported they had become acutely aware of the degree of insularity present in both their personal and academic lives, and that insularity was entrenched within their community and institution. Their growth in awareness so positively characterized in the previous section appeared to be a "doubleedged sword" producing both positive feelings about the intellectual progress they felt they had made, but also anxiety about the extent of the progress that remained to be achieved and the barriers that were firmly in place and which might prevent such progress.

These three themes reflect key characteristics in the process of transformative learning (Mezirow, 1991) and are parallel with the attributes demonstrated by individuals in the intermediate stages of Bennett's model of growth in intercultural sensitivity. Most participants had started to make changes to their teaching practice:

One of the assignments in a grad course - it is an optional assignment - asks people to look at the topic from the literature only using international sources - sources that are outside the North American continent. I will wait and see how that works, but it is partly an effort to do exactly what you are talking about - it is just to say, hang on a minute, there is a whole lot out there and maybe we are not tapping it.

In general, the post-CRIW discussion revealed an array of changes in participants' conceptual and practical understanding of internationalizing the curriculum. The group's enthusiasm for internationalization had been sustained and had even grown from the level reported at the end of the CRIW, as they were now able to envision how they could effectively engage in the process. At the same time, they appeared very aware of, and frustrated by, the larger systemic issues that might impede their progress.

\section{CONCLUSIONS}

Through pre- and post-CRIW questionnaires, interviews and examination of workshop artefacts (e.g., concept maps, daily written feedback), our pilot study documented progressive and substantial growth in understanding of both the concepts of internationalization and of curricular design, an increase in understanding of how the participants might actually change curriculum, and a greater willingness to change. The shifts in assumptions and perspectives and 
the growth in capacity to effect change were in line with the theoretical bases of the original educational intervention designed by Saroyan, Amundsen and colleagues. The outcomes were consistent with the view that in order for educators to act on a particular reform, they must be given the opportunity to construct their own understanding of the reform activity.

In particular, the initial definition of internationalization of the curriculum provided by facilitators as a process by which international elements are infused into course content, international resources are used in course readings and assignments, and instructional methodologies appropriate to a culturally diverse student population are implemented, did not prove to be the most useful framework. Participants displayed a need to engage with the notion of internationalization on a much deeper level embedded in critical pedagogy. The following formulation by Schoorman (2000) provides a much better starting point for future participants to dialogue around the multiple dimensions of internationalization:

Internationalization is an ongoing, counterhegemonic educational process that occurs in an international context of knowledge and practice where societies are viewed as subsystems of a larger, inclusive world. The process of internationalization at an educational institution entails a comprehensive, multifaceted program of action that is integrated into all aspects of education. (p. 2)

Based on the feedback received from participants during the workshop and in the follow-up sessions, the CRIW has been revised and offered again on an annual basis, starting in 2005. We will track the impact of the CRIW sessions over time to assess changes in faculty perceptions and changes in course content, learning outcomes, instructional strategies, and assessment techniques. Student focus groups will be formed in order to evaluate the impact of the internationalized courses on students. Over time, institutional structures will need to be created to allow for the internationalization of the curriculum on a broader scale. As Curro and McTaggart (2003) point out, university management needs to sponsor and promote internationalism and multiculturalism in order to enable changes in institutional culture and allow for internationalization to permeate institutional life. The pilot workshop has acted as a catalyst to start a process of incremental curricular reform that has the potential to ultimately transform students, faculty, and the character of the institution.

\section{NOTES}

1 Three of the course support personnel chose not to participate in this post workshop activity; however, feedback was provided by participants who represented each of the courses in the CRIW. 


\section{REFERENCES}

Amundsen, C., Saroyan, A., \& Frankman, M. (1996). Changing methods and metaphors: A case study of growth in university teaching. Journal of Excellence in Faculty Teaching, 7(3), 3-42.

Bartell, M. (2003). Internationalization of universities: A university culturebased framework. Higher Education, 45(1), 43-70.

Bennett, M. J. (1993). Towards ethnorelativism: A developmental model of intercultural sensitivity. In R. Michael Paige (Ed.), Education for the intercultural experience (pp. 21-71). Yarmouth, ME: Intercultural Press.

Bond, S., Qian, J., \& Huang, J. (2003). The role of faculty in internationalizing the undergraduate curriculum and classroom experience. CBIE Research Millennium Series No. 8. Ottawa: Canadian Bureau for International Education.

Bond, S., \& Thayer Scott, J. (1999). From reluctant acceptance to modest embrace: The internationalization of the undergraduate education. In S. Bond \& J-P. Lemasson (Eds.), A new world of knowledge: Canadian universities and globalization (pp. 45-75). Ottawa: International Development Research Centre.

Borisoff, D. (1997). Sensitizing the educational climate: Communication in the multicultural classroom. Phi Beta Delta International Review, 7, 9-27.

Bremer, L., \& van der Wende, M. (1995). Internationalising the curriculum in higher education. Amsterdam: Nuffic.

Curro, G., \& McTaggart, R. (2003). Supporting the pedagogy of internationalisation. Proceedings of the $17^{\text {th }}$ IDP Australian International Education Conference. Melbourne, Australia. Retrieved August 28, 2004, from http://www.idp.com/ 17aiecpapers/program/wednesday/curriculum4/CurroMcTaggartWed1635_p.pdf

de Wit, H. (1999, Spring). Changing rationales for the internationalisation of higher education. International Higher Education, 15, 2-3.

Eisenchlas, S., \& Trevaskes, S. (2003). Internationalisation at home: Some principles and practices. In A. J. Liddicoat, S. Eisenchlas, \& S. Trevaskes (Eds.), Australian perspectives on internationalising education (pp. 87-102). Melbourne: Language Australia.

Felder, R., \& Brent, R. (1996). Navigating the bumpy road to student-centered instruction. College Teaching, 44(2), 43-47.

Francis, A. (1993). Facing the future: The internationalization of post-secondary institutions in British Columbia. Vancouver: British Columbia Centre for International Education.

Green, M., \& Olson, C. (2003). Internationalizing the campus: A user's guide. Washington, DC: American Council on Education.

Haigh, M. (2003). Internationalising the university curriculum: Response to M.G. Jackson. Journal of Geography in Higher Education, 27(3), 331-340. 
Huang F. (2003). Policy and practice of the internationalization of higher education in China. Journal of Studies in International Education, 7(3), 225-240.

Illeris, K. (2004). The three dimensions of learning. Frederiksberg, Denmark: Roskilde University Press.

Jackson, M.G. (2003). Internationalising the university curriculum. Journal of Geography in Higher Education, 27(3), 325-330.

James, K. (2005). International education: The concept, and its relationship to intercultural education. Journal of Research in International Education, 4(3), 313-332.

Jones, S., \& Sobiecki, P. (2002, July 9). Student-centred learning and international students. Paper presented at the 2002 Sixth Pacific Rim - First Year in Higher Education Conference: Changing Agendas “Te Ao Hurihuri”. Abstract retrieved October 10, 2005, from http://www.fyhe.qut.edu.au/past_papers/papers02/Jones\&SobieckiPaper.doc

Knight, J. (2000). Progress and promise: The 2000 AUCC report on internationalization at Canadian universities. Ottawa: Association of Universities and Colleges of Canada.

Maidstone, P. (1995). Terminology. In International literacy: A paradigm for change (pp. 15-17). Victoria: Province of British Columbia; Ministry of Skills, Training and Labour.

McAlpine, L., \& Harris, R. (2002). Evaluating teaching effectiveness and teaching improvement: A language for institutional policies and development practices. International Journal of Academic Development, 7(1), 7-17.

McAlpine, L., \& Winer, L. (2002). Sustainable faculty development: An Indonesian case study. Innovations in Education and Teaching International, 39(3), 205-216.

Mezirow, J. (1991). Transformative dimensions of adult learning. San Francisco, CA: Jossey-Bass.

Miles, M. B., \& Huberman, A. M. (1994). Qualitative data analysis: An expanded sourcebook (2nd ed.). Thousand Oaks, CA: Sage.

The New London Group. (1996). A pedagogy of multiliteracies: Designing social futures. Harvard Educational Review, 66(1), 60-92.

Ramsden, P. (2003). Learning to teach in higher education (2nd ed.). London: Routledge Falmer.

Ryan, J. (2000). A guide to teaching international students. Oxford, England: The Oxford Centre for Staff and Learning Development.

Samuel, E., \& Burney, S. (2003). Racism, eh? Interactions of South Asian students with mainstream faculty in a predominantly white Canadian university. Canadian Journal of Higher Education, 33(2), 81-114. 
Saroyan, A., \& Amundsen, C. (Eds.). (2004). Rethinking teaching in higher education. Sterling, VA: Stylus Publishing.

Saroyan, A., \& Amundsen, C. (2001). Evaluating university teaching: Time to take stock. Assessment and Evaluation in Higher Education, 26(4), 337-349.

Saroyan, A., Amundsen, C., McAlpine, L., Weston, C., Winer, L., \& Gandell, R. (2004). Tenets underlying our approach to faculty development. In A. Saroyan, \& C. Amundsen (Eds.), Rethinking teaching in higher education (pp. 1-17). Sterling, VA: Stylus Publishing.

Schoorman, D. (2000). What really do we mean by 'internationalization'? Contemporary Education, 71(4), 5-11.

Taylor, J. (2004). Toward a strategy for internationalisation: Lessons and practice from four universities. Journal of Studies in International Education, $8(2), 149-171$.

Wenger, E. (1998). Communities of practice: Learning, meaning, and identity. Cambridge, England: Cambridge University Press.

\section{CONTACT INFORMATION}

Sabine Schuerholz-Lehr

Office of International Affairs

University of Victoria

Victoria, BC V8W 2Y2

E-mail: sabine@uvic.ca

Sabine Schuerholz-Lehr is assistant director of International Affairs at the University of Victoria. She is currently completing a PhD in Educational Studies at the same institution. Her professional practice is directed at supporting faculty and other instructional staff in introducing an international dimension into their curricula both on and off campus. Her doctoral work focuses on the impact of a scholarship program offered by Cuba to students from other lower-income countries.

Dr. Catherine Caws is an assistant professor in the Department of French at the University of Victoria. She conducts research in language teaching, computerassisted language learning, and the development of multi-literacies in higher education. She is currently involved in a collaborative project, funded by the Research and Development Initiative program of the Social Sciences and Humanities Research Council of Canada that seeks to study the learning and teaching impact of a french learning object repository.

Dr. Geraldine Van Gyn is a professor in the Faculty of Education (Kinesiology) and past director of the Learning and Teaching Centre at the University of 
Victoria. Her research program focuses on learning conditions that foster cognitive engagement and includes an extensive examination of the educational outcomes of co-operative education. She has delivered over 150 workshops and seminars on teaching and learning and co-authored STLHE's Green Guide No. 6: Teaching for Critical Thinking.

Dr. Alison Preece is associate professor of Language, Literacy and Early Childhood, Faculty of Education, University of Victoria. For the last decade she has worked extensively in Macedonia, Armenia, Pakistan, and Kyrgyzstan as a volunteer with teachers and teacher educators who are striving to more actively and critically engage their students. She is editor-in-chief of Thinking Classroom/Peremena, an international journal that provides a forum for dialogue for educators world wide.

(NOTE: STLHE is the Society for Teaching and Learning in Higher Education) 